\title{
Dual effect of silymarin on experimental non-alcoholic steatohepatitis induced by irinotecan
}

\author{
Eudmar Marcolino Assis-Júnior ${ }^{\mathrm{a}}$, Anielle Torres Melo a , Venúcia Bruna Magalhães Pereira a , \\ Deysi Viviana Tenazoa Wong ${ }^{\text {b }}$, Nathalia Ribeiro Pinho Sousa ${ }^{a}$, Christiane Mendes Gonçalves Oliveira ${ }^{a}$,

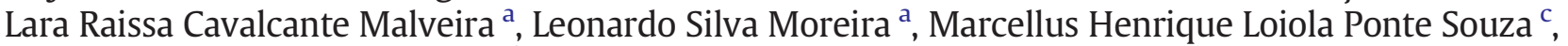 \\ Paulo Roberto Carvalho Almeida ${ }^{\mathrm{b}}$, Roberto César Pereira Lima-Júnior ${ }^{\mathrm{a}, *}$ \\ a Department of Physiology and Pharmacology, Faculty of Medicine, Federal University of Ceará, Brazil \\ b Department of Pathology and Forensic Medicine, Faculty of Medicine, Federal University of Ceará, Brazil \\ ${ }^{c}$ Department of Clinical Medicine, Faculty of Medicine, Federal University of Ceará, Brazil
}

\section{A R T I C L E I N F O}

\section{Article history:}

Received 23 January 2017

Revised 20 April 2017

Accepted 23 April 2017

Available online 26 April 2017

\section{Keywords:}

Irinotecan

Steatohepatitis

Silymarin

Cancer chemotherapy toxicity

Inflammation

Liver

\begin{abstract}
A B S T R A C T
Irinotecan-based regimens are commonly used for treatment of colorectal cancer, which is limited by mucositis and non-alcoholic steatohepatitis (NASH). Silymarin (SIL) prevents fatty liver disease in the clinical setting and in models of liver damage induced chemically. This study investigated the possible effect of SIL on irinotecan (IRI)induced NASH. Swiss female mice were injected with saline (SAL $5 \mathrm{ml} / \mathrm{kg}$ i.p.), IRI ( $50 \mathrm{mg} / \mathrm{kg}$ i.p.), SIL (150 mg/kg p.o.) or IRI (50 mg/kg i.p.) + (SIL 1.5, 15 or $150 \mathrm{mg} / \mathrm{kg}$ p.o.) thrice/week/7 weeks. On the seventh week, blood samples were collected for transaminases assay and livers were collected for histopathology, measurement of the total lipids, malondyadehyde (MDA), non-protein sulfhydryl groups (NPSH), cytokines (IL-1 $\beta$, IL 6 and IL10), 3-nitrotyrosine (N-Tyr) and toll-like receptor 4 (TLR4) immunoexpression, quantification of NF-kB, $\alpha$ smooth muscle actin ( $\alpha$-SMA), and Escherichia coli 16S rRNA gene (RRS) expression. IRI increased liver transaminases, neutrophil infiltration, lipid accumulation, MDA, IL-1ß and IL-6 levels, N-Tyr and TLR4 immunostaining, NF-kB, $\alpha$-SMA expression and RRS versus the SAL group ( $\mathrm{p}<0.05)$. Additionally, SIL $(1.5 \mathrm{mg} / \mathrm{kg}) \mathrm{improved}$ these parameters $(p<0.05)$, except neutrophil infiltration and RSS versus the IRI group. Furthermore, the SIL $(15 \mathrm{mg} / \mathrm{kg}$ ) only improved the inflammatory parameters, the expression of $\alpha$-SMA and RRS versus the IRI group ( $\mathrm{p}<0.05)$. The higher dose of SIL $(150 \mathrm{mg} / \mathrm{kg}$ ) was even more deleterious than the intermediate dose. Therefore, silymarin showed a dual effect on liver damage induced by IRI. Hepatoprotection seems to involve the inhibition of oxidative stress and protein nitrosylation, preventing activation of hepatic fibrosis mechanisms.
\end{abstract}

(C) 2017 Elsevier Inc. All rights reserved.

\section{Introduction}

Colorectal Cancer (CRC) is the third most common type of cancer among men (10\% of total cases) and the second among women $(9.2 \%$ of total cases). Although the majority of cases (55\%) occur in developed regions, the highest mortality rates occur in less developed regions (52\% of deaths) (WHO-World Health Organization, 2004).

The main site of CRC metastasis is the liver in about $30 \%$ of patients (Kuvshinov and Fong, 2007). Clinical management of metastatic CRC involves tumor resection (Costa et al., 2014). Non-resectable tumors can become resectable by the use of conversion therapy, which is mainly based on irinotecan or oxaliplatin combined with 5-Fluorouracil

\footnotetext{
* Corresponding author at: Departamento de Fisiologia e Farmacologia, Faculdade de Medicina, Universidade Federal do Ceará, Rua Cel Nunes de Melo, 1127, Rodolfo Teófilo, 60430-270 Fortaleza, Ceará, Brazil.

E-mail address: robertocesar@ufc.br (R.C.P. Lima-Júnior).
}

(Bismuth et al., 1996; Adam et al., 2004; Pozzo et al., 2004). However, irinotecan-based regimens are related to limiting side effects such as intestinal mucositis (IM) (Ikuno et al., 1995; Freitas, 2007). In addition, about 1 in 12 patients undergoing irinotecan treatment develop non-alcoholic steatohepatitis (NASH), representing a 3.45-fold increased risk for those under chemotherapy treatment (Robinson et al., 2012), which might limit metastasectomy. Histopathological damage criteria were established by Kleiner et al. (2005), who consider steatosis, lobular inflammation and vacuolization as important parameters for NASH diagnosis, while fibrosis and portal infiltration are considered indicators of severe disease (Kleiner et al., 2005). Costa and co-workers developed an experimental model of irinotecan-related NASH characterized by oxidative stress, inflammatory infiltrate, lipid accumulation, fibrosis and hepatic failure (Costa et al., 2014).

Silymarin is a naturally-occuring, polyphenol-rich antioxidant, which acts as a free radical scavenger (Fraschini et al., 2002). It is reported that silymarin reversibly inhibits P-450 cytochrome enzymes 
(Fraschini et al., 2002), stabilizes mitochondrial (Bindoli et al., 1997) and microsomal membranes (Trouillas et al., 2008). Polyak et al. (2007) and Kim et al. (2013) reported anti-inflammatory and immunomodulatory effects of silymarin with the involvement of NF- $\kappa$ B inhibition (Lee et al., 2013) and over-expression of immunomodulators such as IL-10 and IFN- $\gamma$ (Wilasrusmee et al., 2002). In addition, Täger et al. (2001) reported that silymarin treatment over-expressed the endogenous IL-1 $\beta$ inhibitor (IL-1ra). However, the effects of silymarin vary according to the dose and route of administration.

Silymarin hepatic protection has been widely demonstrated in animal models and in the clinical setting (Cacciapuoti et al., 2013; Zhang et al., 2013; Trouillas et al., 2008; Chen et al., 2012). It is effective in the treatment of obesity-related NASH (Cacciapuoti et al., 2013), prevents the establishment of alcoholic steatohepatitis (Zhang et al., 2013), and protects against chemically-induced liver damage and fibrosis by carbon tetrachloride (Trouillas et al., 2008) and thioacetamide (Chen et al., 2012).

In the present study we aimed to evaluate the effects of silymarin on irinotecan-induced non-alcoholic steatohepatitis.

\section{Materials and methods}

\subsection{Chemicals and antibodies}

Irinotecan hydrochloride (Evoterin ${ }^{\circledR}$, Evolabis, São Paulo, Brazil, vial of $100 \mathrm{mg}$ ); Silymarin S0292 (Sigma-Aldrich, MO, USA); Monoclonal primary antibody rabbit anti-nitrotyrosine (Life Technology, NY, USA); Monoclonal primary antibody rabbit anti TLR-4 (Life Technology, NY, USA); Polyclonal primary antibody anti-NF-kB NLS rabbit (Santa Cruz Biotechnology, CA, USA); Polyclonal primary antibody Rabbit AntiActin $\beta$ (Santa Cruz Biotechnology, CA, USA); Primary Antibody Monoclonal Goat Anti- $\alpha$-SMA (Sigma-Aldrich, MO, USA); Secondary antibody linked to alkaline phosphatase anti-rabbit IgG (Sigma Aldrich, MO, USA); Secondary antibody linked to alkaline phosphatase anti-goat IgG (Sigma-Aldrich, MO, USA); ImunoCruz - Anti-rabbit ABC kit (Santa Cruz Biotechnology, CA, USA).

\subsection{Animals}

Swiss mice, weighing between 20 and $25 \mathrm{~g}$, and obtained from the animal facility at Federal University of Ceará were used. The animals had free access to drinking water and food and were kept in a controlled temperature $\left(22 \pm 2{ }^{\circ} \mathrm{C}\right)$ environment with a light-dark cycle (12 h/12 h). All animal care and experimental procedures complied with the laboratory animal care and use principles outlined by the $\mathrm{Na}-$ tional Institutes of Health (NIH publication no. 85-23, revised 1985) and were approved by the local Ethics in Animal Research Committee (CEPA) of the Federal University of Ceará (Protocol number 21/12).

\subsection{Experimental design}

The animals were divided into six experimental groups $(\mathrm{n}=8-10)$ : group 1 - SAL: Saline $5 \mathrm{ml} / \mathrm{kg}$, p.o. 1 h before saline $5 \mathrm{ml} / \mathrm{kg}$ i.p; group 2 SIL: Silymarin $150 \mathrm{mg} / \mathrm{kg}$, p.o. $1 \mathrm{~h}$ before saline $5 \mathrm{ml} / \mathrm{kg}$ i.p.; group 3 - IRI: Saline $5 \mathrm{ml} / \mathrm{kg}$, p.o. $1 \mathrm{~h}$ before irinotecan $50 \mathrm{mg} / \mathrm{kg}$, i.p.; group 4 - S1.5: Silymarin $1.5 \mathrm{mg} / \mathrm{kg}$ p.o. $1 \mathrm{~h}$ before irinotecan $50 \mathrm{mg} / \mathrm{kg}$ i.p.; group 5 S15: Silymarin $15 \mathrm{mg} / \mathrm{kg}$ p.o. $1 \mathrm{~h}$ before irinotecan $50 \mathrm{mg} / \mathrm{kg}$ i.p.; group 6 - S150: Silymarin $150 \mathrm{mg} / \mathrm{kg}$ p.o. $1 \mathrm{~h}$ before irinotecan $50 \mathrm{mg} / \mathrm{kg}$ i.p. The animals were injected three times a week on alternate days. On the sixth day of each week the animals received silymarin or saline reinforcement. This schedule of treatment was continued for seven consecutive weeks. The survival rate (\%) of the animals was recorded.

\subsection{Serum concentration of liver transaminases}

The mice were anaesthetised using $2.5 \%$ tribromo-ethanol solution (10 $\mathrm{ml} / \mathrm{kg}$, i.p.) for blood sample collection at the retro orbital plexus. After centrifugation (at $100 \times \mathrm{g}$ for $10 \mathrm{~min}$ ), the plasma was obtained for alanine and aspartate aminotransferase (ALT and AST) biochemical analysis following the manufacture's guidebook (Labtest Diagnostica commercial kits, Minas Gerais, Brazil).

\subsection{Histopathological analysis}

Liver samples were fixed in $10 \%$ formalin buffered solution, dehydrated and embedded in paraffin. Microtome sections (5 mm) were stained using hematoxylin-eosin (H\&E) and mounted on $24 \mathrm{~mm}^{2}$ coverslips, to be examined by optical microscopy $(\times 100)$. The slides were analysed by an experienced pathologist who was unaware of treatment and group sorting. NASH diagnosis and graduation were made using NASH Activity Score (NAS), as proposed by Kleiner et al. (2005). The concomitant presence of the following three histological parameters is necessary to diagnose NASH: steatosis $(<5 \%$ score $0 ; 5-$ $33 \%$ score 1 ; $33-36 \%$ score 2 ; > 66\% score 3 ); lobular inflammation (no infiltrated by field score 0 , mild infiltration score 1 ; moderate infiltration score 2; intense infiltration score 3 ) and hepatocyte ballooning (Score $0=$ none, score $1=$ mild ballooning, score $2=$ severe ballooning).

In addition, neutrophil infiltration sites in all histopathologic slides were counted blind by two independent collaborators (10 fields). The first field choice was random; the following fields were contiguous to the previous field.

\subsection{Liver lipid contents}

Lipid content was assayed using the Bligh and Dyer (1959) method. Briefly, samples were homogenized in chloroform:methanol (1:2), $1.9 \mathrm{ml}$ per $100 \mathrm{mg}$ tissue sample, before adding more chloroform $(0.63 \mathrm{ml})$ and stirring. Distilled water $(0.63 \mathrm{ml})$ was added to reach a final proportion of 2:2:1 chloroform:methanol:water. The mixture was centrifuged at room temperature, $200 \times \mathrm{g}$ for $2 \mathrm{~min}$, obtaining a two-phase system (polar above, nonpolar below). The lower phase was placed into a tare tube and evaporated at $100{ }^{\circ} \mathrm{C}$. Total lipid was expressed in mg of lipids/g of liver.

\subsection{Malondialdehyde assay (MDA)}

Liver samples were homogenized in $1.15 \% \mathrm{KCl}$ solution (10\% homogenate). A homogenate aliquot $(500 \mu \mathrm{l})$, placed in a test tube, was mixed with $3 \mathrm{ml}$ 1\% H3PO4 and $0.6 \mathrm{ml}$ 1\% thiobarbituric acid (TBA). This mixture was placed in a water bath ( $45 \mathrm{~min}$ ) and cooled in ice, n-butanol ( $4 \mathrm{ml}$ ) was added, and the mixture was vortexed ( $1 \mathrm{~min}$ ) and centrifuged at $1200 \mathrm{~g}$ for $15 \mathrm{~min}$. The butanolic fraction was placed in a cuvette and read in spectrophotometer at 520 and $535 \mathrm{~mm}$ and the difference between the two readings was used to calculate the MDA, based on the molar extinction coefficient $(13,700 \mathrm{M} / \mathrm{cm}$ ) (Mihara and Uchiyama, 1978).

\subsection{Non-protein sulfhydryl groups (NP-SH)}

400 ul aliquots of $10 \%$ homogenate liver samples in cold sodium EDTA $(0.02 \mathrm{M})$ were added to $320 \mu \mathrm{l}$ of distilled water and $80 \mu \mathrm{l}$ of trichloroacetic acid (TCA - 50\%). The samples were then centrifuged at $1200 \mathrm{~g}$ for $15 \mathrm{~min}$, and $200 \mathrm{ul}$ from the supernatant was placed in a test tube with $0.4 \mathrm{M}$ Tris buffer $\mathrm{pH} 8.9$ (400 uL) and 0.01 M DTNB (10 $\mathrm{ul}$ ) and incubated at room temperature for $5 \mathrm{~min}$. The samples were then read in spectrophotometer $(412 \mathrm{~nm})$. A calibration curve was produced using reduced glutathione. NP-SH concentration was calculated 
using linear regression and is expressed in NP-SH/tissue ( $\mathrm{mg} / 500 \mathrm{mg}$ ) (Boyd et al., 1979).

\subsection{Detection of cytokines IL-1 $\beta$, IL-6 and IL-10 by ELISA}

IL-1 $\beta$, IL-6 and IL-10 levels were assayed by ELISA (Cunha et al., 1993). The liver samples were homogenized (Safieh-Garabedian et al. 1995). A 96-well plate was coated with an antibody against the desired interleukin ( $4 \mu \mathrm{g} / \mathrm{ml}$, DuoSet ELISA Development kit R\&D Systems) overnight at $4{ }^{\circ} \mathrm{C}$. After blocking unspecific binds with BSA, the sample and standard were loaded in duplicate and incubated at $4{ }^{\circ} \mathrm{C}$ for $2 \mathrm{~h}$ (Adam et al., 2004). The plates were washed 3 times with PBS-Tween $20,0.1 \% \mathrm{v} / \mathrm{v}$ (washing step). After washing, specific detection biotinylated antibody (diluted 1:1000 with assay buffer 1\% BSA, R\&D System, USA) was added to the wells, followed by another $2 \mathrm{~h}$ incubation at 4 ${ }^{\circ} \mathrm{C}$. The plates were washed as before, and $100 \mu \mathrm{l}$ of streptavidin-HRP diluted $1: 200$ were added, followed by $100 \mu \mathrm{l}$ of substrate solution ( $1: 1$ mixture of $\mathrm{H}_{2} \mathrm{O}_{2}$ and tetramethylbenzidine; R\&D System, USA), the plate was then incubated in the dark at room temperature for $20 \mathrm{~min}$. The reaction was stopped by addition of $2 \mathrm{~N} \mathrm{H}_{2} \mathrm{SO}_{4}$, and the absorbance was measured at $450 \mathrm{~nm}$. The results are expressed in $\mathrm{pg} / \mathrm{g}$ of tissue and reported as the mean $\pm \mathrm{SEM}$.

\subsection{Immunohistochemistry}

Immunohistochemical analyses of the liver samples for iNOS, N-Tyr and TLR4 were performed as follows: Histological specimens were deparaffinised and then hydrated. After hydration, the slides were submerged in citrate buffer ( $\mathrm{pH} \mathrm{6.0)}$ ), and heated at $100^{\circ} \mathrm{C}$ for $15 \mathrm{~min}$ for antigen recovery. After cooling to room temperature, the slides were washed in PBS three times. The slides were submerged in 3\% hydrogen peroxide to block endogenous peroxidases and washed again. The primary antibody was incubated for $12 \mathrm{~h}$ (rabbit anti-iNOS antibodySanta Cruz Biotechnology, Santa Cruz, CA, anti-N-Tyr and Anti-TLR4 Life Technology, Life $\left.{ }^{\circledR}, N Y\right)$, and diluted in either PBS - BSA 5\% ratio 1: 400 (iNOS and TLR4) or 1: 800 (N-Tyr). The slides were washed again, before incubation of the biotinylated secondary antibody (30 min, room temperature), anti-rabbit IgG diluted in PBS-5\% BSA at a ratio of $1: 200$. Following further washing the slides were incubated with $A B C$ complex (30 min) (horseradish peroxidase Standard). The slides were finally washed as before, and DAB/peroxide ( $2 \mathrm{~min}$ ) was used to colour the proteins, the $\mathrm{DAB} /$ peroxide stain confreres a characteristic brown colour to the positive cells. Harry's hematoxylin was used as a contrast stain, before rinsing the slides in distilled water and dehydrating with a graded series of alcohol and xylene, and mounting. Quantitative reaction analysis, following Yeoh et al. (2005) parameters, was carried out by a pathologist using a light microscope. TLR4 positive cells were counted in ten microscope fields in each sample, similarly, N-tyr positive areas were quantified in ten fields of each sample using the image processing software Fiji (Schindelin et al., 2012).

\subsection{Quantitative real-time PCR ( $q P C R$ )}

To assay enteric bacteria translocation, liver samples were collected in sterile conditions and homogenized in Trisol buffer for DNA extraction using the Qiagen kit according to the manufacturer's specifications. The polymerase chain reaction was performed as described below:

E. coli 16S rRNA gene (RRS), associated with Escherichia coli detection, was detected using IQ5 Real-Time PCR Detection System (Bio-Rad Laboratories, USA) (Quetz et al., 2012). The housekeeping gene used was PPIA peptidylprolyl isomerase A (Tatsumi et al., 2008). The primer pairs for mouse were as follows: 16SrRNA (Forward $-5^{\prime}$ GTGGAAAAACCTCGTCCAGA-3'; Reverse: 5'-GCTCGGCTTCCAGTAFFGAG$3^{\prime}$ ) and PPIA (Forward: 5'-GACATGGAGAAGATCTGGCA-3'; Reverse: 5'GGTCTTTACGGATGTCAACG-3'). The conditions used were: for 16SrRNA, $95{ }^{\circ} \mathrm{C}-20^{\prime \prime}, 63{ }^{\circ} \mathrm{C}-20^{\prime \prime}$ and $72{ }^{\circ} \mathrm{C}-45^{\prime \prime}$ and for PPIA, $95{ }^{\circ} \mathrm{C}-20^{\prime \prime} 58^{\circ} \mathrm{C}-20^{\prime \prime}$ and $72{ }^{\circ} \mathrm{C}-45^{\prime \prime}$. iQ SYBR Green Supermix (10 uL) (Bio-Rad, San Diego, CA, USA), each primer $(2 \mu \mathrm{l})(0.2 \mu \mathrm{M})$, cDNA samples $(3 \mu \mathrm{l})$ and nuclease-free water to a final volume of $20 \mu \mathrm{l}$, were used in the reaction. All amplifications resulted in a melting curve, used to ensure the amplification specificity and to detect primer-dimer formation or other non-specific product. Tested genes' quantification cycles $(\mathrm{Cq})$ were exported to Microsoft Excel (Microsoft, USA) and the RSS relative gene expression levels were calculated according to $2-\Delta \Delta \mathrm{CT}$ methodology, where $\Delta \Delta \mathrm{CT}=$ (CT Target Gene - CT housekeeping gene in the treated group)/(target gene CT - CT of the housekeeping gene control), with PPIA as the housekeeping gene (Livak and Schmittgen, 2001)

\subsection{Western blot}

Animals' livers were homogenized in RIPA buffer (50 mM Tris; $150 \mathrm{mM} \mathrm{NaCl} ; 1 \mathrm{mM}$ EDTA; $1 \%$ Triton) and centrifuged at $1500 \mathrm{~g}$ for $10 \mathrm{~min}$, before their supernatants were separated into appropriately labelled Eppendorf tubes. The total protein in each sample was assayed using a BioRad $\circledast$ Kit, following the manufacturer's instructions. Equal amounts of total protein were loaded onto a SDS-PAGE gel and run at $150 \mathrm{~V}$. The proteins were then transferred to a nitrocellulose membrane using the BioRad system. The membrane was incubated in $5 \%$ skimmed milk (NESTLÉ ${ }^{\circledR}$ ) in TBS-T buffer (Tris-NaCl with 1\% Tween 20) for $2 \mathrm{~h}$. Afterwards, the membranes were washed 3 times (10 min each) with TBS-T buffer. Next, they were incubated with the respective primary antibodies (anti-NF-kB NLS rabbit (1:600); Rabbit Anti-Actin $\beta$ (1:5000) Santa Cruz Biotechnology, CA, USA; Goat Anti- $\alpha$-SMA (1:600) - SigmaAldrich, MO, USA), and diluted in 5\% BSA-TBS buffer (Tris-NaCl). The incubation was carried out over-night at $4{ }^{\circ} \mathrm{C}$ with gentle agitation. The membranes were then washed as described above and incubated with secondary antibodies (alkaline phosphatase anti-rabbit IgG (1:1000); alkaline phosphatase anti-goat IgG (1:1000) - Sigma-Aldrich, MO, USA), diluted in 5\% skimmed milk-TBS-T for $2 \mathrm{~h}$. Later, the membranes were washed again and developed using the alkaline-phosphatase subtract BCIP®/NBT (Sigma Aldrich).

\subsection{Statistical analysis}

Data are expressed as the mean \pm standard error of the mean (SEM), except for the histopathological scores which are reported as median values (minimum-maximum). Data were analysed using one-way ANOVAs followed by the Newman-Keuls's test or the Kruskal-Wallis test, followed by Dunn's test, as appropriate. The survival curve was expressed as a percentage of surviving animals and the log-rank (Mantel-Cox) test was used to determine differences between survival curves. The level of statistical significance was set at $5 \%(p<0.05)$.

\section{Results}

3.1. Clinical-like aspects of irinotecan-induced-NASH and liver functional parameters

The treatment with irinotecan caused higher mortality versus saline group (Fig. 1). While the intermediate and low doses of silymarin did not interfere with mortality, the highest dose of silymarin increased the death ratio to nearly $100 \%$ and therefore this dose was not used for subsequent assays.

Irinotecan significantly $(\mathrm{p}<0.05)$ increased serum transaminase levels (Fig. 2A) and histopathologic damage scores (Table 1) with lipid accumulation (Fig. 2B), and increased in neutrophil infiltrate (Fig. 2C) and expression of Smooth Muscle Alpha Actin ( $\alpha$-SMA) (Fig. 2D) when compared to the saline group. Neutrophil infiltration, steatosis, cell necrosis and vacuolation can be observed in photomicrography (Fig. 3). 


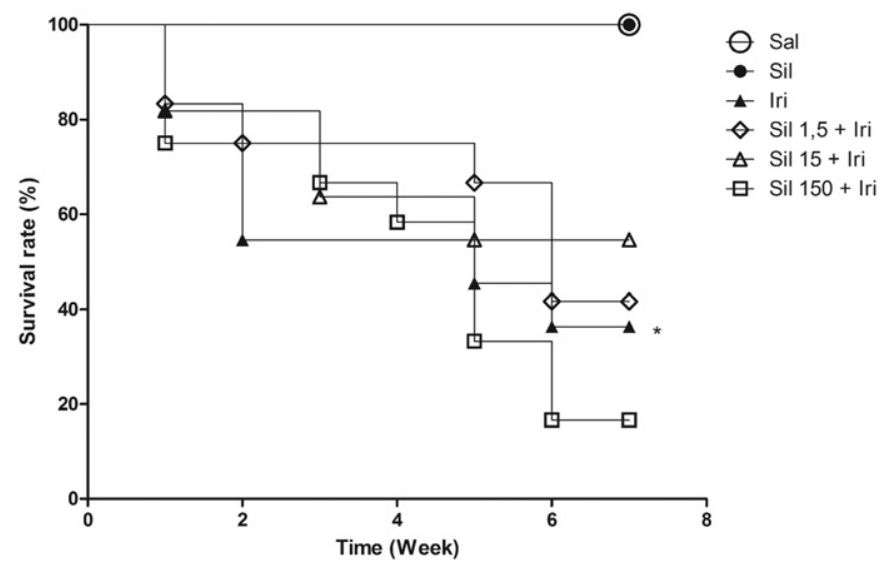

Fig. 1. Irinotecan increased mice mortality, and silymarin was not able to attenuate this parameter. The graph represents the weekly increased mice death ratio (Kaplan Meier test). Mantel-Cox log-rank for survival curves were used for comparison. ${ }^{*} \mathrm{p}<0.05$ vs. saline group (negative control).

The lower dose of silymarin significantly improved almost all liver function markers (Fig. 2A, B and D), except the neutrophil infiltrate (Fig. 2C). In this group, the liver parenchyma was unharmed, with observable hepatocyte cord arrangement and sinusoids with preserved architecture (Fig. 3). The intermediate dose presented large and diffused histopathologic damage, with necrotic areas and compromised architecture (Fig. 3). This intermediate dose promoted higher serum concentration of transaminases (Fig. 2A) and greater expression of $\alpha$ -
Table 1

Histopathological changes ranked by Kleiner' score. Irinotecan significantly increased total Kliener' score versus saline group. Low doses of silymarin was capable of preventing these changes. The results are reported as medians $\pm \operatorname{SEM}(\mathrm{n}=5$ per group) and analysed using Kruskal-Wallis and Dunn's test.

\begin{tabular}{lllll}
\hline & Kleiner's score & & & \\
\cline { 2 - 5 } Groups & Lobular inflammation & Steatosis & Ballonization & Total \\
\hline Saline & $1(0-1)$ & $0(0-1)$ & $0(0-1)$ & $1(0-2)$ \\
Silymarin & $0,5(0-1)$ & $0(0-1)$ & $0(0-0)$ & $0,5(0-2)$ \\
Irinotecan & $1,5(1-2)$ & $0(0-1)$ & $1,5(1-2)^{*}$ & $3(3-4)^{*}$ \\
Sil 1,5 & $1,5(1-2)$ & $0(0-1)$ & $0(0-0)^{\#}$ & $2(1-2)^{\#}$ \\
Sil 15 & $1(1-3)$ & $0(0-0)$ & $0(0-2)$ & $1(1-5)$ \\
\hline
\end{tabular}

${ }^{*} \mathrm{p}<0.05$ vs. saline

$\# \mathrm{p}<0.05$ vs. irinotecan.

SMA (Fig. 2D), but reduced the neutrophil infiltration count (Fig. 2C) and lipid accumulation (Fig. 2B). These findings were significantly different from irinotecan group $(\mathrm{p}<0.05)$.

\subsection{Oxidative stress plays a role in pathophysiology but its control is not} sufficient to prevent disease progression

To investigate the role of oxidative stress in IRI-related NASH, samples of each group were used in MDA, NPSH and nitrotyrosine (N-Tyr) assays. MDA presence indicates oxidative stress, since this aldehyde is the main the sub-product of the membrane's polyunsaturated fatty acid peroxidation (Zhu et al., 2014). Its presence aggravates the oxidation by causing denaturation and membrane peroxidation (Zhang et al., 2013).
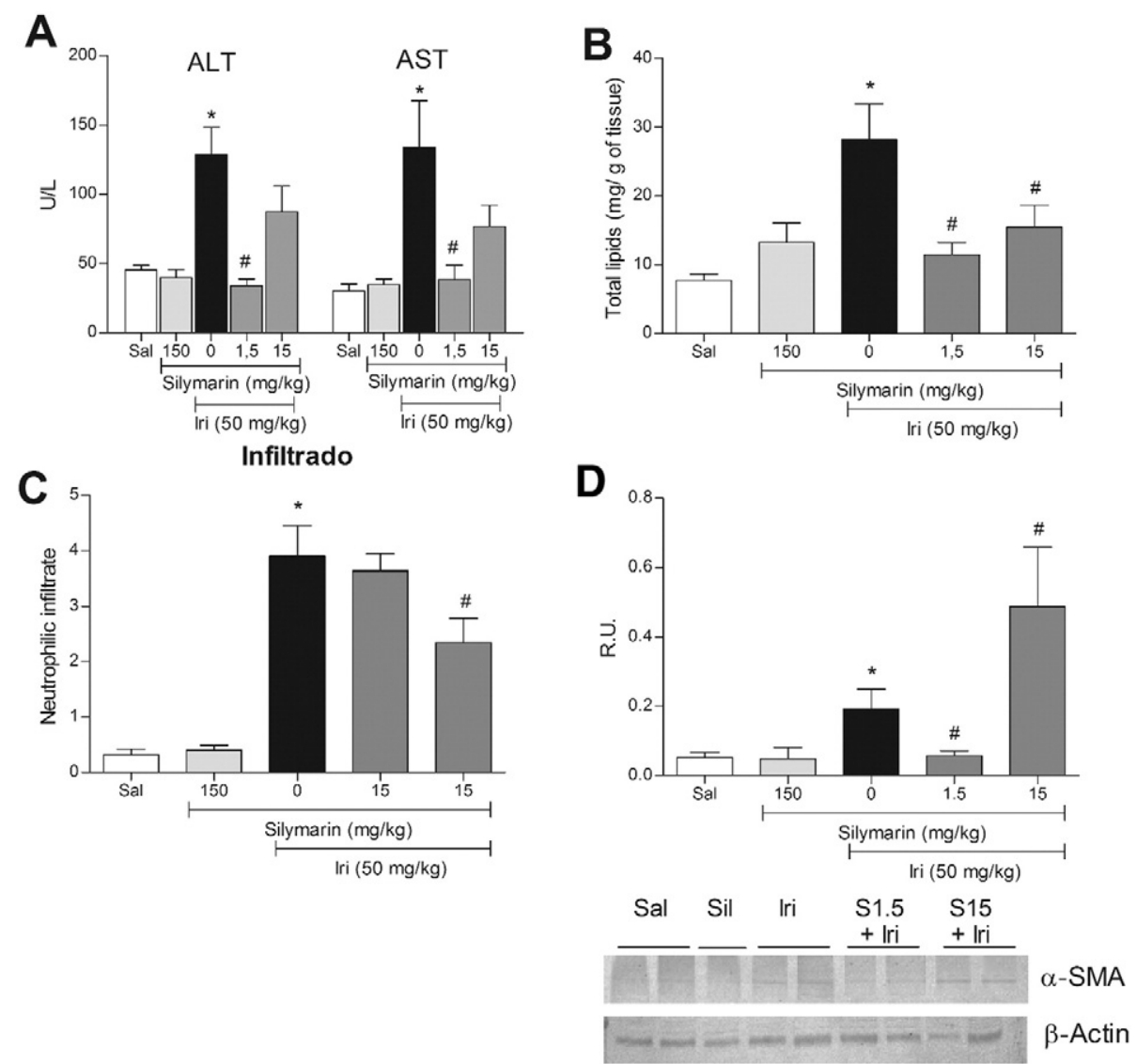

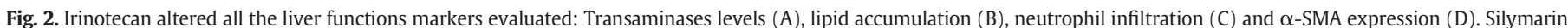

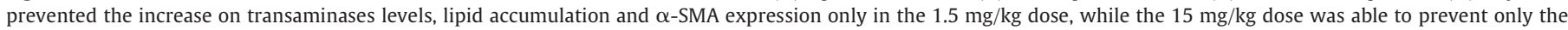

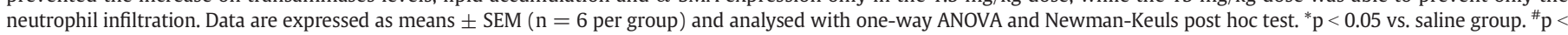
0.05 vs. irinotecan group. 

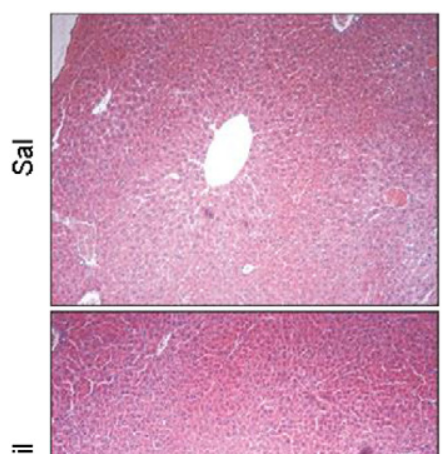

$\overline{\bar{s}}$

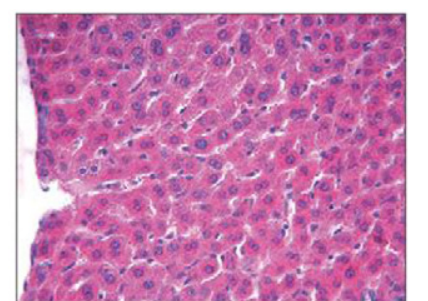

드
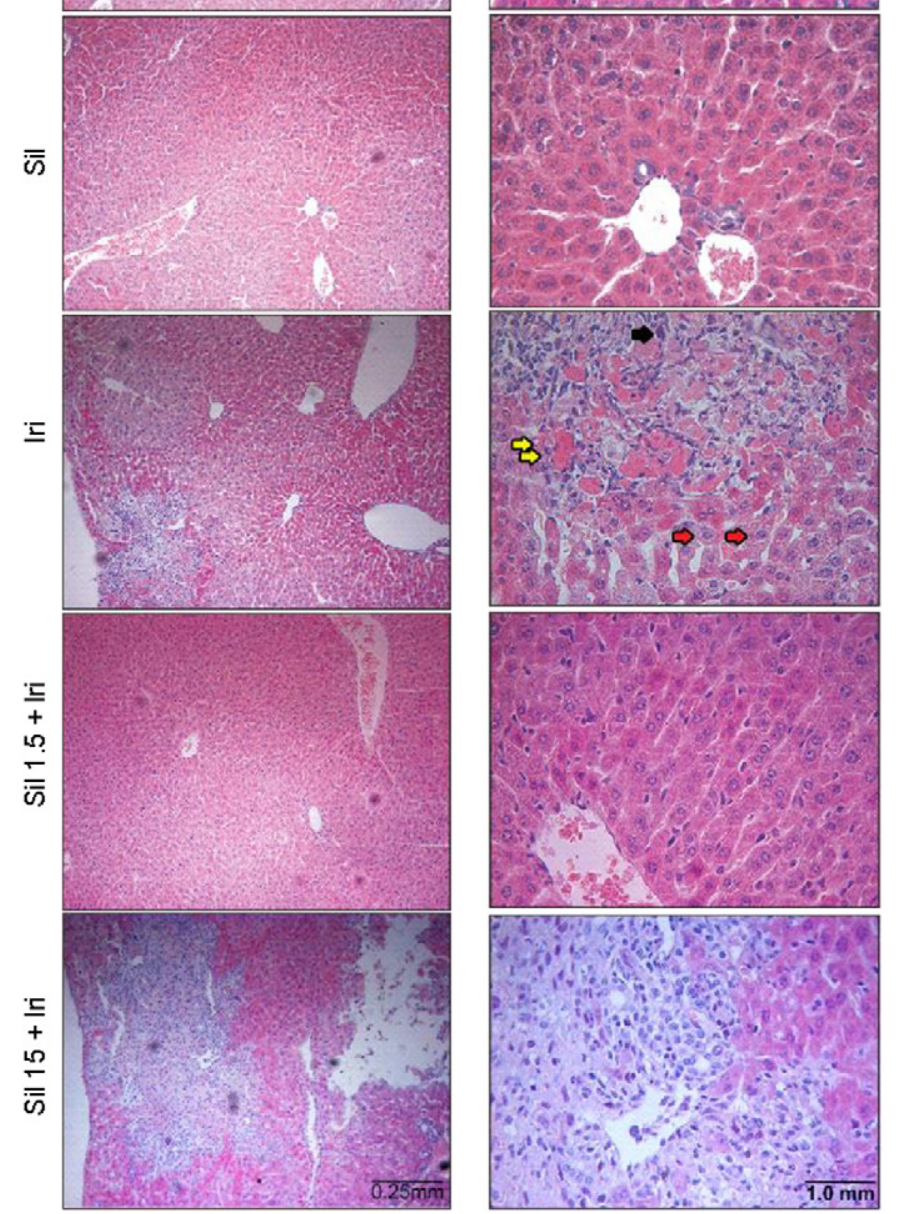

Fig. 3. Silymarin improved microscopic injury in liver during irinotecan induced-NASH. The irinotecan injection induced liver parenchyma destruction with ballooning (red arrows), steatosis (yellow arrows), infiltration (black arrow) and necrotic areas. Pretreatment with silymarin $1.5 \mathrm{mg} / \mathrm{kg}$ preserved the liver architecture, although there are numerous inflammatory infiltrates. Silymarin at dose of $15 \mathrm{mg} / \mathrm{kg}$ showed great individual variability and very advanced lesion patterns which were not consistent with NASH. It was observed large necrotic areas. Specimens in this picture were stained with H\&E, magnification 40 and $100 \times$.

Another important oxidative stress parameter is the staining for $\mathrm{N}$ Tyr. When peroxynitrite reacts with normal tissue proteins, it modifies tyrosine residues to generate nitrotyrosine. Then, peroxynitrite action can be indirectly detected by N-Tyr staining in the liver tissue (Huie and Padmaja, 1993).

Irinotecan increased $(\mathrm{p}<0.05)$ the levels of MDA (Fig. 4A) and N-Tyr (Fig. 4C), while decreased NP-SH (Fig. 4B) versus the saline injected group. Lower doses of silymarin reduced the MDA accumulation (Fig. 4A) and the N-Tyr staining (Fig. 4C), but increased the total NPSH available (Fig. 4B) in comparison with the irinotecan group. The intermediate doses had similar effects. The only parameter that was not significantly different than the saline group was MDA accumulation ( $p>0.05$ ). Representative images from the immunostaining for N-Tyr show strong staining in the irinotecan group compared to saline-treated group, which was markedly attenuated by all doses of silymarin (Fig. 4D).
3.3. Control of bacteria accumulation in the liver depends on the dose of silymarin and adequate anti-inflammatory and immune-modulatory response

Irinotecan treatment increased the expression of inflammatory markers in the liver when compared to saline-treated animals ( $\mathrm{p}<$ 0.05). Fig. 5 shows that IL-6, IL-1 $\beta$ and NFKB are increased in irinotecan injected mice's livers (Fig. 5A, B and D). Silymarin treatment showed a reduced NFKB (Fig. 5D) and IL-6 (Fig. 5A) expression, but only $1.5 \mathrm{mg} / \mathrm{ml}$ doses reduced the expression of IL-1 $\beta$ (Fig. 5B). IL-10 did not change on irinotecan injection, but intermediate doses of silymarin significantly overexpressed this cytokine (Fig. 5C).

\subsection{Bacteria seem to contribute to the pathophysiology of irinotecan-relat-} ed NASH

RSS-16S gene expression showed the presence of bacteria in the liver of animals treated with irinotecan versus saline injected animals (Fig. 6A). Animals that received a low dose of silymarin, but not those treated with intermediate doses, showed a significantly reduced number of RSS-16S copies compared to the irinotecan group (Fig. 6A). Immunostaining for TLR4 confirmed our PCR data, which showed that irinotecan enhanced the staining for TLR4 (Fig. 6B) versus the saline group, and that lower doses of silymarin notably reduced it (Fig. 6B). Representative photomicrographs from the immunostaining for TLR4 show a higher number of positively stained cells in the irinotecan group, and the low dose silymarin-treated animals displayed reduced immunoexpression (Fig. 6C).

\section{Discussion}

This study describes the effect of silymarin on Irinotecan-related NASH. Our results showed that drug has a dual effect, showing preventive characteristics in low doses and enhancing liver damage in higher doses. Silymarin alone did not cause toxicity, even in high doses.

The same damage pattern associated with irinotecan injection as described previously (Costa et al., 2014) was reproduced in this study. Irinotecan injections resulted in higher lipid content and inflammation in the liver, as similarly shown by Costa et al. (2014). According to Costa et al. (2014), irinotecan causes intestinal damage, allowing translocation of Gram negative bacteria to the liver. Translocating bacteria cause tissue damage associated with inflammation and massive neutrophil infiltration, oxidative burst with high levels of ROS, and mitochondria damage culminating in lipid accumulation and lipid peroxidation, which in turn enhances free radical levels and exacerbates local damage in a vicious cycle. Silymarin pre-treatment reduced the accumulation of fat in the liver of the mice that received irinotecan. The consensus on fatty liver appearance is that lipid accumulation can involve either one, or a combination of three causes: a higher blood concentration of fatty acids due to a fat rich diet or adipocyte break down; greater endogenous synthesis of fat, or a mitochondrial dysfunction (Chitturi and Farrell, 2001). As found here, there was no difference in dietary conditions between groups, or any reason for higher fatty acids synthesis. It is therefore possible that lipid accumulation in the liver occurred due to mitochondrial dysfunction. Previous studies have demonstrated that silymarin prevents mitochondrial dysfunction by stabilising the mitochondrial membrane, and improving fluidity and membrane potential state (Zhu et al., 2014; Trouillas et al., 2008). However, there are no data concerning a direct role of silymarin in lipid metabolism. This supports the assumption that lipid accumulation occurs due to mitochondrial dysfunction.

Low doses of silymarin prevented the appearance of clinical signs highly correlated to NASH (Kleiner et al., 2005; Kleiner and Brunt, 2012) such as lobular inflammation, steatosis and vaccuolation, and also prevented the expression of $\alpha$-SMA, a known fibrosis marker associated with advanced NASH. On the other hand, higher doses promoted 


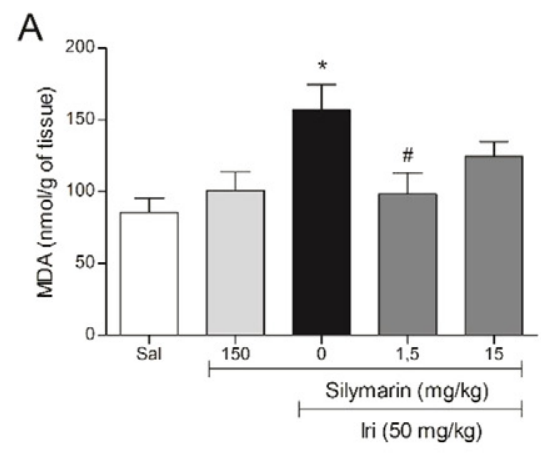

D
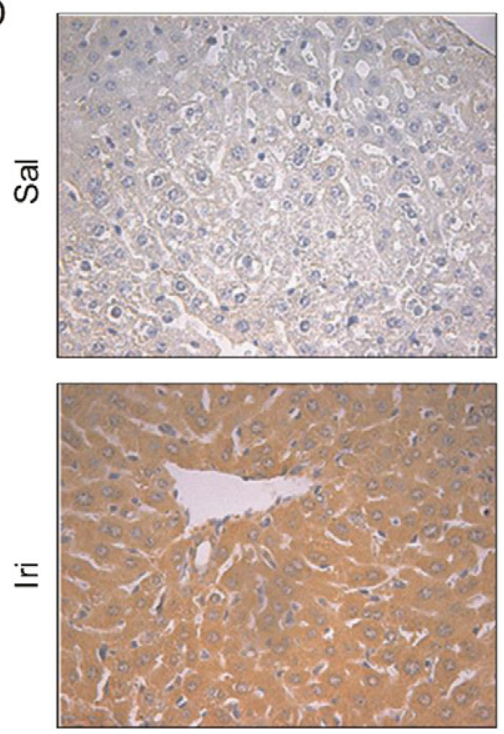

$\mathrm{B}$

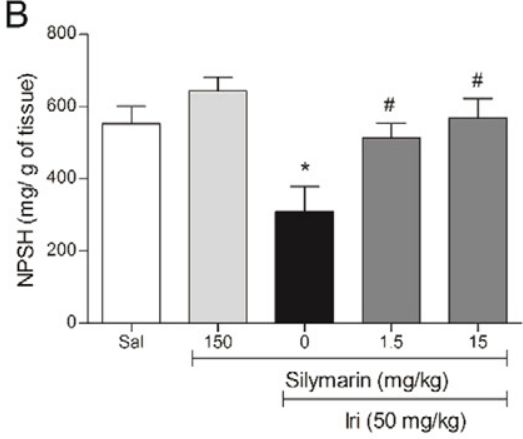

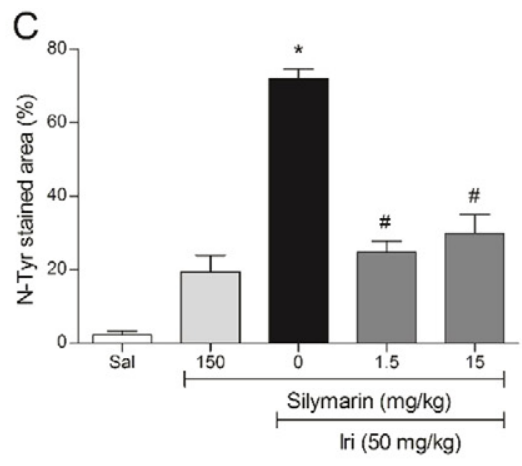
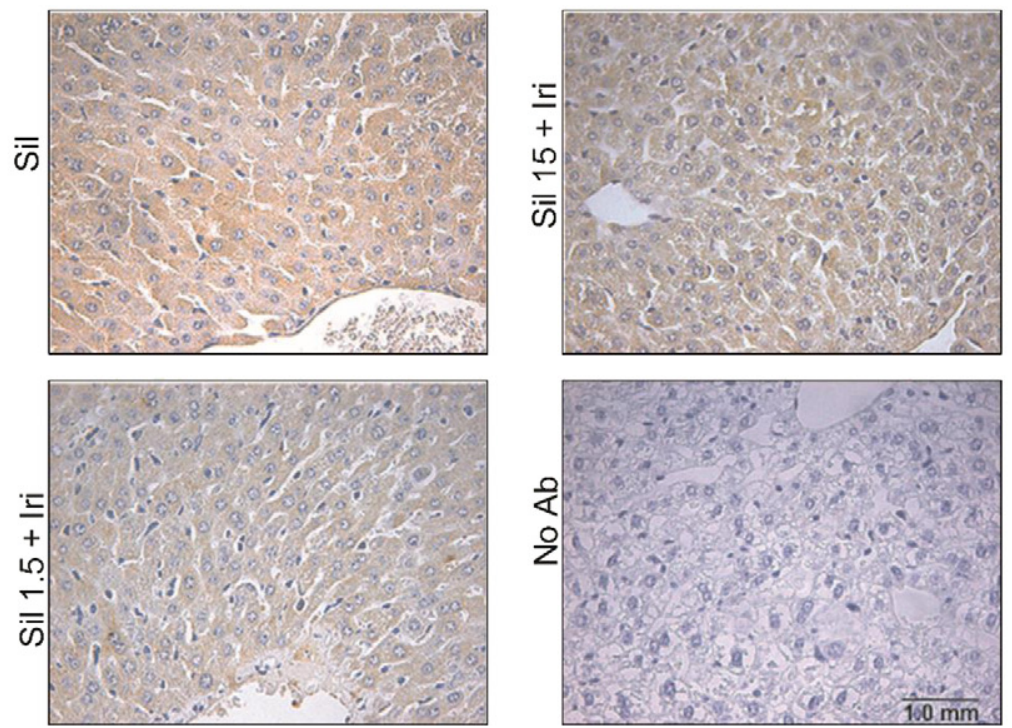

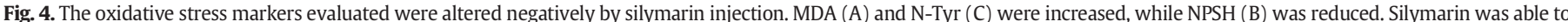

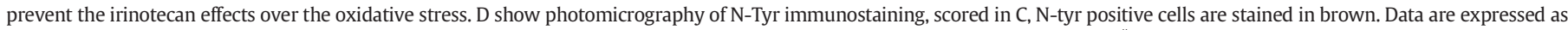
means \pm SEM ( $n=6$ per group) and analysed with one-way ANOVA and Newman-Keuls post hoc test. ${ }^{*} \mathrm{p}<0.05$ vs. saline group. ${ }^{*} \mathrm{p}<0.05$ vs. irinotecan group.

liver histopathological damage, with increased levels of serum hepatic transaminases and higher expression of $\alpha$-SMA.

Both low and high doses of silymarin showed low staining for N-tyr and high levels of NP-SH. Higher doses showed lower neutrophil infiltrate and lower expression of IL-6, suggesting damage caused directly by bacteria; action on the liver cells. The similarities and differences between groups highlight the importance of a basal oxidation level, as low doses of silymarin prevented oxidative stress, but did not interfered with some inflammatory functions, such as neutrophil accumulation, which is essential to control infections. It is possible to speculate that intermediate doses of silymarin reduced the neutrophils' oxidative capacity and infiltration ability. Thus bacterial infection was not properly handled, resulting in significant liver damage.

Local inflammation is also likely involved in lipid accumulation. Costa et al. (2014) previously showed that irinotecan induces several inflammatory and oxidative events which precede lipid accumulation in irinotecan-related NASH. In addition, several reports show that inflammation inhibits the lipoprotein lipase in hepatocytes (Butterwith and Griffin, 1989). Inflammation can also lead to excessive production of ROS (Abbas and Lichtman, 2011), damaging mitochondrial membranes. This indicates a potential beneficial use for anti-inflammatory drugs fin treating NASH.

Silymarin prevented some inflammatory events, agreeing with literature data that report itsanti-inflammatory and immunomodulatory effects (Fraschini et al., 2002). It was demonstrated that silymarin overexpresses IL-1ra and down-regulates IL-6 (Täger et al., 2001). The groups treated with silymarin showed reduced levels of IL-6 and NF- $\kappa \mathrm{B}$ in comparison to irinotecan. However, the intermediate dose group failed to down-regulate IL-1 $\beta$. A proper inflammatory response is essential for adequate bacterial clearance, which may explain the liver damage observed in the group that received higher doses of silymarin. Additionally, IL-6 shows a role in liver regeneration, so its downregulation could compromise damage recovery. Accordingly, IL-6 knockout mice fail to regenerate the liver after hepatectomy due to lack of DNA synthesis (Cressman et al., 1996). IL-6 downregulation could therefore have contributed to the extensive damage observed in animals treated with higher silymarin doses.

Lower IL-6 expression could either be due to reduced nuclear localization of NF-kB, (Barnes and Karin, 1997), or negative modulation by anti-inflammatory cytokines such as IL-10. Knolle et al. (1997) showed that exogenous IL-10 interferes with IL-6 expression in a dose-dependent manner. Although IL-10 expression is also enhanced by transcription factor NF-kB, it can be alternatively regulated by cAMP (Opal et al., 1998). It is well-known that IL-10 is released at later stages of the inflammatory process as a natural mechanism against exacerbated proinflammatory stimuli (Howard et al., 1993). Silymarin is reported to increase IL-10 expression (Wilasrusmee et al., 2002), therefore similar mechanisms may be operating in this study.

Conversely, high levels of IL-10 in combination with larger quantities of antioxidants can be challenging to a bacterially-infected liver. As oxidative bursts are essential in the bactericidal effect of neutrophils, this mechanism would not properly function in the case when high doses of antioxidants are used. Additionally, Excessive IL-10 in the liver can cause a shift in the expression of adhesion proteins at the sinusoids, 

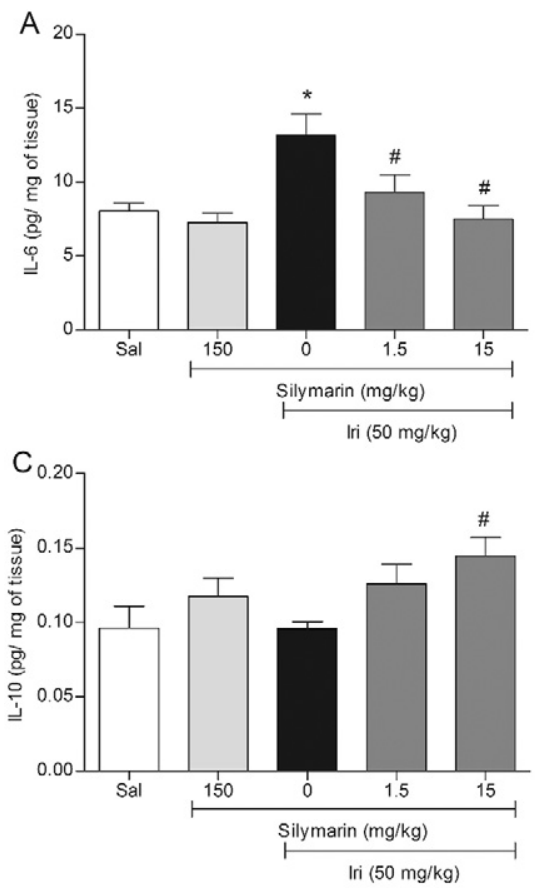

B

D
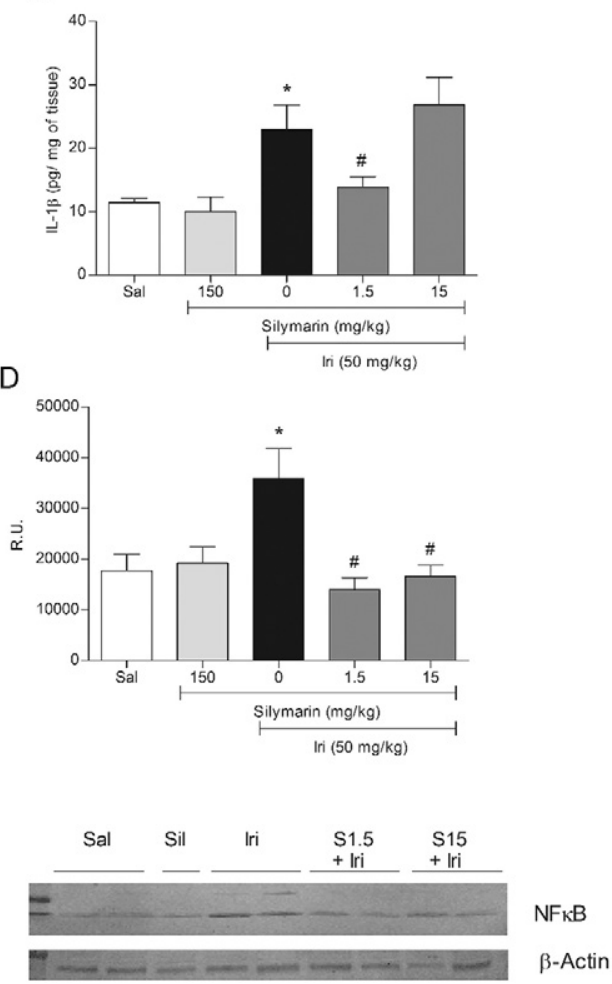

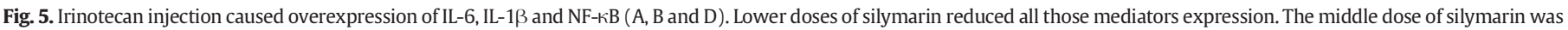

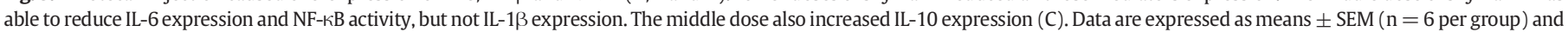
analysed with one-way ANOVA and Newman-Keuls post hoc test. ${ }^{*} \mathrm{p}<0.05$ vs. saline group. ${ }^{*} \mathrm{p}<0.05$ vs. irinotecan group.

decreasing the diapedesis rate to the liver (Menezes et al., 2009). This may explain the lower neutrophil infiltration observed in the groups injected with high doses of silymarin.
Oxidative burst inhibition could also explain the liver damage observed in the intermediate dose group. Costa et al. (2014) showed that Escherichia coli translocates from the gut to the liver during
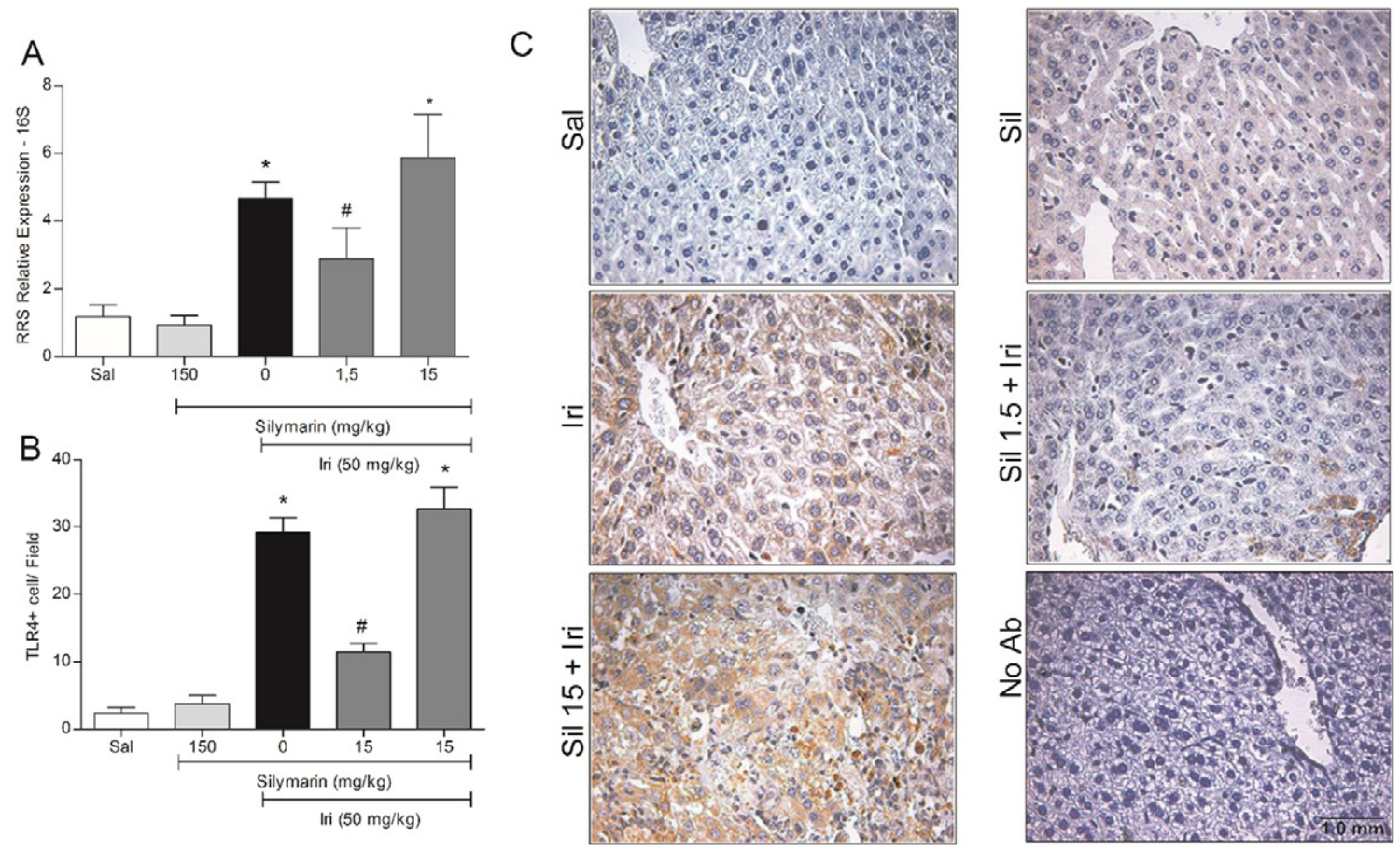

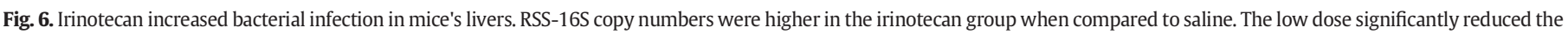

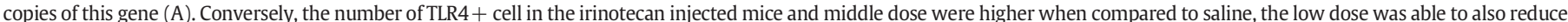

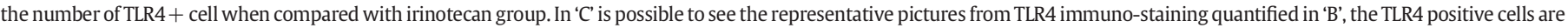

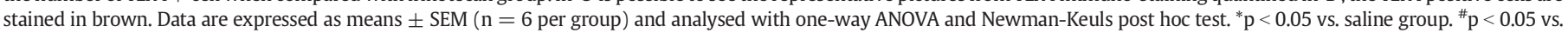
irinotecan group. 
steatohepatitis. Bacterial LPS activates inflammatory response in a TLR4-dependent pathway (Raetz et al., 1991). This pathway acts as the first line of defence against infection. However other types of cellular damage are also associated with E. coli infection. E. coli uses the Type Three Secretion System (T3SSs) to import effectors into the cytoplasm of eukaryotic cells. Those effectors are recognised by mitochondrial associated protein (Map) or by the EspF effectors phosphorylating $\mathrm{N}$ WAS and WAVE-2, leading to cytoskeletal rearrangement, mitochondrial dysfunction, apoptosis and necrosis (Coburn et al., 2007). Then, bacterial interaction with liver cells and secretory mechanisms might explain the damage observed in the Sil 15 + Iri group.

The discrepancy between IL-1 $\beta$ being reduced at low doses, but not at intermediate doses, could be explained by the involvement of cell processing. IL-1 $\beta$ is produced physiologically as a precursor, pro-IL-1 $\beta$, which must be cleaved to become an active molecule and be secreted, which explains its relatively fast release following a trigger event, such as bacterial infection (Dinarello, 1998). As it is found pre-formed, the transcription activity of NF- $\kappa$ B would not be essential to IL-1 $\beta$ release. That does not exclude the possibility of an alternative pathway through MAP3K/ERK JNK/AP-1, for example (Samavati et al., 2009). In addition, silymarin is reported to supress the IL- $1 \beta$ signal, but not its expression (Täger et al., 2001).

In the clinical setting, silymarin daily doses range from 280 to $800 \mathrm{mg}$. Taking into account the difference between the protective effects of low doses of silymarin in oppose to increased risk of liver damage with its intermediate and high doses, clinical trials are highly recommended in order to assess the optimal dose to be used in patients to prevent irinotecan-related hepatotoxicity. Then, based on present results, it is reasonable to consider that the therapeutic index of silymarin might be shortened when administered together with irinotecan. However, with the current knowledge of the animal doses in this co-administration scenario $(1.5 \mathrm{mg} / \mathrm{kg}$ as therapeutic dose and $15 \mathrm{mg} / \mathrm{kg}$ as Lowest Observed Adverse Effect Level - LOAEL - in mice), it is impossible to determine a starting dose for the clinical trial with co-administration, based on standard risk management practise. Taken into account the ten-fold uncertainty factor for interspecies extrapolation and ten-fold uncertainty factor for LOAEL to NOAEL (No Observed Adverse Effect Level) extrapolation, the NOAEL in human would be $0.15 \mathrm{mg} / \mathrm{kg}$, much lower than the therapeutic dose of $1.5 \mathrm{mg} / \mathrm{kg}$. According to Blanchard and Smoliga (2015), interspecies dose scaling must be scientifically justified using a broader physiologic, pharmacokinetic, and toxicology data. Then, it might be unethical to dose human at $1.5 \mathrm{mg} / \mathrm{kg}$ in co-administration scenario based on the current knowledge.

In summary, the lowest dose of silymarin protected the liver tissue against the damage induced by irinotecan. Silymarin-related protection seems to be mediated by the control of oxidative stress without compromising the innate and adaptive immune functions. Here, we showed the effectiveness of a clinically used drug in an atypical application. In addition to better understanding the pathophysiology of NASH induced by irinotecan, the present study provides new insights on how to modulate the balance of pro- and anti- inflammatory cytokines and oxidative stress to control infection in that context. However an investigation of the impact of antibiotics in this animal model is still necessary.

\section{Conflicts of interest}

The authors indicate that they have no potential conflicts of interest.

\section{Acknowledgments}

We are grateful to Maria Silvandira Freire for her technical assistance. This study was supported by $\mathrm{CNPq}$ (Conselho Nacional de Desenvolvimento Científico e Tecnológico, grant number: 307143/20147) and FUNCAP (Fundação Cearense de Apoio ao Desenvolvimento Científico, grant number: PR2-0101-00054.01.00/15). RCPLJ is a CNPq fellowship holder.

\section{References}

Abbas, A.K., Lichtman, A.H., 2011. Basic Immunology: Functions and Disorders of the Immune System. Saunders/Elsevier, Philadelphia, PA.; London.

Adam, R., Delvart, V., Pascal, G., Valeanu, A., Castaing, D., Azoulay, D., Giacchetti, S., Paule, B., Kunstlinger, F., Ghémard, O., Levi, F., Bismuth, H., 2004. Rescue surgery for unresectable colorectal liver metastasisdownstaged by chemotherapy: a model to predict long-term survival. Ann. Surg. 240 (4), 644-657.

Barnes, P.J., Karin, M., 1997. Nuclear factor-kappaB: a pivotal transcription factor in chronic inflammatory diseases. N. Engl. J. Med. 336 (15), 1066-1071.

Bindoli, A., Cavallini, L., Siliprandi, N., 1997. Inhibitory action of silymarin of lipid peroxide formation in rat liver mitochondria and microsomes. Biochem. Pharmacol. (26), 2405-2409.

Bismuth, H., Adam, R., Lévi, F., Farabos, C., Waechter, F., Castaing, D., Majno, P. e Engerran, L., 1996. Resection of nonresectable liver metastases from colorectal cancer after neoadjuvant chemotherapy. Ann. Surg. 224 (4), 509-522.

Blanchard, O.L., Smoliga, J.M., 2015. Translating dosages from animal models to human clinical trials-revisiting body surface area scaling. FASEB J. 29 (5), 1629-1634.

Bligh, E.G., Dyer, W.J., 1959. A rapid method of total lipid extraction and purification. Can. J. Biochem. Physiol. 37 (8), 911-917.

Boyd, S.C., Sasame, H.A., Boyd, M.K., 1979. High concentration of glutathione in glandular stomach: possible implications for carcinogenesis. Science 205 (1979), 1010-1112.

Butterwith, S.C., Griffin, H.D., 1989. The effects of macrophage-derived cytokines on lipid metabolism in chicken (Gallus domesticus) hepatocytes and adipocytes. Comp. Biochem. Physiol. A Comp. Physiol. 94 (4), 721-724.

Cacciapuoti, F., Scognamiglio, A., Palumbo, R., Forte, R., Cacciapuoti, F., 2013. Silymarin in non alcoholic fatty liver disease. World J. Hepatol. 5 (3), 109-113.

Chen, I.S., Chen, Y.C., Chou, C.H., Chuang, R.F., Sheen, L.Y., Chiu, C.H., 2012. Hepatoprotection of silymarin against thioacetamide-induced chronic liver fibrosis J. Sci. Food Agric. 92 (7), 1441-1447.

Chitturi, S., Farrell, G.C., 2001. Etiopathogenesis of nonalcoholic steatohepatitis. Semin. Liver Dis. 21 (1), 27-41.

Coburn, B., Sekirov, I., Finlay, B.B., 2007. Type III secretion systems and disease. Clin. Microbiol. Rev. 20 (4), 535-549.

Costa, M.L., Lima-Júnior, R.C., Aragão, K.S., Medeiros, R.P., Marques-Neto, R.D., de Sá Grassi, L., Leite, L.L., Nunes, L.G., de Mesquita Neto, J.W., de Castro Brito, G.A., de Souza, M.H., de Almeida, P.R., Ribeiro, R.A., 2014. Chemotherapy-associated steatohepatitis induced by irinotecan: a novel animal model. Cancer Chemother. Pharmacol. 74 (2).

Cressman, D.E., Greenbaum, L.E., DeAngelis, R.A., Ciliberto, G., Furth, E.E., Poli, V., Taub, R., 1996. Liver failure and defective hepatocyte regeneration in interleukin-6-deficient mice. Science (New York, N.Y.) 274 (5291), 1379-1383.

Cunha, F.Q., Boukili, M.A., Motta, J.I.B., Vargaftig, B.B., Ferreira, S.H., 1993. Blockade by fenspiride of endotoxin-induced neutrophil migration in the rat. Eur. J. Pharmacol $238,47-52$.

Dinarello, C.A., 1998. Interleukin-1 $\beta$, interleukin-18, and the interleukin-1 $\beta$ converting enzymea. Ann. N. Y. Acad. Sci. 856 (1), 1-11.

Fraschini, D.F., Demartini, G., Esposti, D., 2002. Pharmacology of Silymarin. Clin. Drug Invest. 22 (1), 51-65.

Freitas, H.C., 2007. Envolvimento da interleucina-18 (IL-18) na patogênese da mucosite gastrintestinal induzida pelo cloridrato de irinotecano (CPT-11). 104f. Dissertação (Mestrado em Farmacologia). Faculdade de Medicina, Universidade Federal do Ceará, Fortaleza.

Howard, M., Muchamuel, T., Andrade, S., Menon, S., 1993. Interleukin 10 protects mice from lethal endotoxemia. J. Exp. Med. 177 (4), 1205-1208.

Huie, R.E., Padmaja, S., 1993. The reaction of no with superoxide. Free Radic. Res. Commun. 18 (4), 195-199.

Ikuno, N., Soda, H., Watanabe, M., Oka, M., 1995. Irinotecan (CPT-11) and characteristic mucosal changes in the mouse ileum and cecum. J. Natl. Cancer Inst. 87 (24), 1876-1883.

Kim, B.-R., Seo, H.-S., Ku, J.-M., Kim, G.-J., Jeon, C.Y., Park, J.H., Jang, B.-H., Park, S.-J., Shin, Y.C., Ko, S.-G., 2013. Silibinin inhibits the production of pro-inflammatory cytokines through inhibition of NF-kB signaling pathway in HMC-1 human mast cells. Inflamm Res. 62, 941-950.

Kleiner, D.E., Brunt, E.M., 2012. Nonalcoholic fatty liver disease: pathologic patterns and biopsy evaluation in clinical research. Semin. Liver Dis. 32 (1), 3-13.

Kleiner, D.E., Brunt, E.M., Van Natta, M., Behling, C., Contos, M.J., Cummings, O.W., Ferrell, L.D., Liu, Y.C., Torbenson, M.S., 2005. Design and validation of a histological scoring system for nonalcoholic fatty liver disease. Hepatology 41 (6), 1313-1321.

Knolle, P.A., Loser, E., Protzer, U., Duchmann, R., Schmitt, E., Zum Buschenfelde, K.-H.M. Rose-John, S., Gerken, G., 1997. Regulation of endotoxin-induced IL-6 production in liver sinusoidal endothelial cells and Kupffer cells by IL-10. Clin. Exp. Immunol. 107 (3), 555-561.

Kuvshinov, B., Fong, Y., 2007. Surgical Therapy of Liver Metastasis. Semin Oncologia 34 (3), 177-185.

Lee, M.-H., Huang, Z., Kim, D.J., Kim, S.-H., Kim, M.O., Lee, S.-Y., Xie, H., Park, S.J., Kim, J.Y., Kundu, J.K., Bode, A.M., Surh, Y.-J., Dong, Z., 2013. Direct targeting of MEK1/2 and RSK2 by silybin induces cell-cycle arrest and inhibits melanoma cell growth. Cancer Prev. Res. (Phila.) 6 (5), 455-465.

Livak, K.J., Schmittgen, T.D., 2001. Analysis of relative gene expression data using realtime quantitative PCR and the 2(-Delta Delta C(T)) Method. Methods 25 (4) $402-408$.

Menezes, G.B., Lee, W.-Y., Zhou, H., Waterhouse, C.C.M., Cara, D.C., Kubes, P., 2009. Selective down-regulation of neutrophil Mac-1 in endotoxemic hepatic microcirculation via IL-10. J. Immunol. 183 (11), 7557-7568 Baltimore, Md.: 1950.

Mihara, M., Uchiyama, M., 1978. Determination of malonaldehyde precursor in tissues by thiobarbituric acid test. Anal. Biochem. 86 (1), 271-278. 
Opal, S.M., Wherry, J.C., Grint, P., 1998. Interleukin-10: potential benefits and possible risks in. Clin. Infect. Dis. 27 (6), 1497-1507.

Polyak, S.J., Morishima, C., Shuhart, M.C., Wang, C.C., Liu, Y., Lee, D.Y.-W., 2007. Inhibition of T-cell inflammatory cytokines, hepatocyte NF-kappaB signaling, and HCV infection by standardized Silymarin. Gastroenterology 132 (5), 1925-1936.

Pozzo, C., Basso, M., Cassano, A., Quirino, M., Schinzari, G., Trigila, N., Vellone, M., Giuliante, F., Nuzzo, G. e Barone, C., 2004. Neoadjuvant treatment of unrectable liver disease with irinotecan and 5- fluorouracil plus folinic acid in colorectal câncer patients. Ann. Oncol. 15 (6), 933-939.

Quetz, J., da, Lima, S.I.F., Havt, A., Prata, M.M., Cavalcante, P.A., Medeiros, P.H., Cid, D.A. Moraes, M.L., Rey, L.C., Soares, A.M., Mota, R.M., Weigl, B.H., Guerrant, R.L., Lima, A.A., 2012. Campylobacter jejuni infection and virulence-associated genes in children with moderate to severe diarrhoea admitted to emergency rooms in northeastern Brazil. J. Med. Microbiol. 61 (Pt 4), 507-513.

Raetz, C.R., Ulevitch, R.J., Wright, S.D., Sibley, C.H., Ding, A., Nathan, C.F., 1991. Gram-negative endotoxin: an extraordinary lipid with profound effects on eukaryotic signal transduction. FASEB J. 5 (12), 2652-2660.

Robinson, S.M., Wilson, C.H., Burt, A.D., Manas, D.M., White, S.A., 2012. Chemotherapy-associated liver injury in patients with colorectal liver metastases: a systematic review and meta-analysis. Ann. Surg. Oncol. 19 (13), 4287-4299.

Safieh-Garabedian, B., Poole, S., Allchorne, A., Winter, J., Woolf, C.J., 1995. Contribution of interleukin- 1 beta to the inflammationinduced increase in nerve growth factor levels and inflammatory hyperalgesia. Br. J. Pharmacol. 115, 1265-1275.

Samavati, L., Rastogi, R., Du, W., Hüttemann, M., Fite, A., Franchi, L., 2009. STAT3 tyrosine phosphorylation is critical for interleukin 1 beta and interleukin- 6 production in response to lipopolysaccharide and live bacteria. Mol. Immunol. 46 (8-9), 1867-1877.
Schindelin, J., Arganda-Carreras, I., Frise, E., Kaynig, V., Longair, M., Pietzsch, T., Preibisch, S., Rueden, C., Saalfeld, S., Schmid, B., Tinevez, J.Y., White, D.J., Hartenstein, V., Eliceiri, K., Tomancak, P., Cardona, A., 2012. Fiji: an open-source platform for biological-image analysis. Nat. Methods 9 (7), 676-682.

Täger, M., Dietzmann, J., Thiel, U., Neumann, K.H., Ansorge, S., 2001. Restoration of the cellular thiol status of peritoneal macrophages from CAPD patients by the flavonoids silibinin and silymarin. Free Radic. Res. 34 (2), 137-151.

Tatsumi, K, Ohashi, K. Taminishi, S, Okano, T, Yoshioka, A Shima, M, 2008. Reference gene selection for real-time RT-PCR in regenerating mouse livers. Biochem. Biophys. Res. Commun. 374 (1), 106-110.

Trouillas, P., Marsal, P., Svobodová, A., Vostálová, J., Gazák, R., Hrbác, J., Sedmera, P., Kren, V., Lazzaroni, R., Duroux, J.L., Walterová, D., 2008. Mechanism of the antioxidant action of silybin and 2,3-dehydrosilybin flavonolignans: a joint experimental and theoretical study. J. Phys. Chem. A 112 (5), 1054-1063.

WHO-World Health Organization, 2004. Disponível em. http://www.who.int/cancer/en/ (Accessed in: 14/08/2014).

Wilasrusmee, C., Kittur, S., Shah, G., Siddiqui, J., Bruch, D., Wilasrusmee, S., Kittur, D.S., 2002. Immunostimulatory effect of Silybum marianum (milk thistle) extract. Med. Sci. Monit. 8 (11), BR439-BR443.

Zhang, W., Hong, R., Tian, T., 2013. Silymarin's protective effects and possible mechanisms on alcoholic fatty liver for rats. Biomol. Ther. 21 (4), 264-269.

Zhu, S.Y., Dong, Y., Tu, J., Zhou, Y., Zhou, X.H., Xu, B., 2014. Silybum marianum oil attenuates oxidative stress and ameliorates mitochondrial dysfunction in mice treated with Dgalactose. Pharmacogn. Mag. 10 (Suppl. 1), S92-S99. 